\title{
Solid residue and by-product yields from acid-catalysed conversion of poplar wood to levulinic acid
}

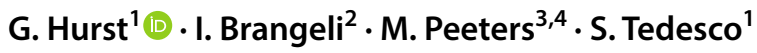

Received: 25 July 2019 / Accepted: 26 November 2019 / Published online: 6 December 2019

(C) The Author(s) 2019

\begin{abstract}
This study examines the yields of solid residue and by-product from the microwave-assisted acid hydrolysis of lignocellulosic poplar wood for levulinic acid production. The aim of this study was to optimise levulinic acid production via response surface methodology (RSM) and also investigate the effect of reaction conditions on other products such as furfural, solid residue, formic acid and acetic acid yields. A maximum theoretical levulinic acid yield of $62.1 \%(21.0 \mathrm{wt} \%)$ was predicted when reaction conditions were $188^{\circ} \mathrm{C}, 126 \mathrm{~min}$ and $1.93 \mathrm{M}$ sulphuric acid, with a corresponding solid residue yield of 59.2 wt $\%$. Furfural from the hydrolysis of hemicellulose was found to have significantly degraded at the optimum levulinic acid yield conditions. The investigation of formic acid yields revealed lower formic acid yields than stoichiometrically expected, indicating the organic acid reactions under microwave-assisted hydrolysis of lignocellulose. The solid residue yields were found to increase significantly with increasing reaction time and temperature. The solid residue yields under all conditions exceeded that of levulinic acid and, therefore, should be considered a significant product alongside the high-value compounds. The solid residue was further examined using IR spectra, elemental analysis and XRF for potential applications. The overall results show that poplar wood has great potential to produce renewable chemicals, but also highlight all by-products must be considered during optimization.
\end{abstract}

Keywords Biorefining $\cdot$ Catalysis $\cdot$ Levulinic acid $\cdot$ Solid residues $\cdot$ Microwave $\cdot$ Acid hydrolysis

Electronic supplementary material The online version of this article (https://doi.org/10.1007/s11696-019-01013-3) contains supplementary material, which is available to authorized users.

G. Hurst

GEORGE.HURST2@stu.mmu.ac.uk

1 Department of Mechanical Engineering, School of Mechanical Engineering, Manchester Metropolitan University, Dalton Building, Chester Street, Manchester M1 5GD, UK

2 Department of Chemical Engineering, Polytechnic School of the University of São Paulo, Avenida Professor Lineu Prestes, 580, Blocos 18-23, São Paulo, Brazil

3 Division of Chemistry and Environmental Science, John Dalton Building, Faculty of Science and Engineering, Manchester Metropolitan University, Chester Street, Manchester M15GD, UK

4 School of Chemical Engineering, Newcastle University, Newcastle upon Tyne NE1 7RU, UK

\section{Introduction}

Recently, integrated biorefining and bioenergy processes have been under development to maximise the extractable value from biomass in the form of green platform chemicals and to support the establishment of a low carbon economy. The potential of second-generation biochemicals produced from abundant non-food crops to contribute to the deployment of a bio-based industry has been recognised (Kumar et al. 2008). Catalytic processes, including acid hydrolysis, partially decompose the lignocellulose into individual sugars before conversion into a range of platform chemicals. The conversion of lignocellulosic biomass with the use of acid catalysts has been investigated for the production of levulinic acid and furfural, from cellulose and hemicellulose fractions of biomass, respectively (Shen and Wyman 2011; Galletti et al. 2012; Dussan et al. 2013; Yu and Tsang 2017; Chen et al. 2018; Kłosowski et al. 2019). Both levulinic acid and furfural have been recognised among the top 30 platform chemicals by the United States Department of Energy (Moriarty et al. 2016). Levulinic acid and furfural can be used as 
building blocks for a variety of applications such as fuel additives, solvents and polymers (Mukherjee et al. 2015; Xiong et al. 2019).

Acid catalysis of lignocellulosic biomass involves the hydrolysis of the cellulose and hemi-cellulose to C6 and C5 sugars, respectively. The acidic conditions subsequently catalyse the dehydration of these sugars into furfural and 5-hydroxymethylfurfural (5-HMF), respectively, at elevated temperatures of $160-220^{\circ} \mathrm{C}$. In aqueous conditions, 5-HMF is then rehydrated to levulinic acid and formic acid in equimolar amounts (Girisuta et al. 2007). Mineral acids such as sulphuric acid and hydrochloric acid are reported to reach levulinic acid and furfural theoretical yields between 50 and $80 \%$ from a broad range of lignocellulosic biomass (Dussan et al. 2013; Chen et al. 2017; Kang et al. 2018). Despite such high conversion efficiencies, acid hydrolysis of sugarbased and lignocellulosic biomass has been proven to lead to the co-production of solid residues (Melligan et al. 2012; Zandvoort et al. 2013).

Solid residues are typically composed of hydrolysisresistant material, primarily acid-insoluble lignin (Sharma et al.), and also contain condensation products from FF and reactive intermediaries (e.g. 5-HMF), known as catalytically derived humins. Humins are polymeric carbonaceous degradation products formed during the acid-catalysed dehydration of sugars, intermediaries and platform chemicals (Patil et al. 2012; Zandvoort et al. 2013). The formation of recalcitrant furan rich humins has been found to account for $10-50 \%$ of carbon losses during acid hydrolysis and reducing both levulinic acid and furfural yields (Runge and Zhang 2012; Tsilomelekis et al. 2016). Additionally, high temperatures associated with acid catalysis can cause carbonization and aromatisation of lignocellulose, as well as catalyse the polymerisation of acid-soluble lignin and sugars (Matsushita et al. 2004; Dussan et al. 2016). Solid residue yields from acid catalysis of Miscanthus spp. and bamboo have been reported to be between 33 and $40 \mathrm{wt} \%$ (Melligan et al. 2012; Sweygers et al. 2018). Zandvoort et al. (2013) modelled humin yields, using response surface methodology (RSM), accomplishing yields up to $36 \mathrm{wt} \%$. Several applications for solid residues as fuel, building material and as feedstock for pyrolysis, with bio oil yields of 10-20\% have been investigated in recent years (Agarwal et al. 2017; Mija et al. 2017; Cao et al. 2019). Whilst the underlying reaction mechanisms for the acid catalysis of cellulose and hemicellulose to high-value chemicals is well understood, there is minimal literature to date on the effects of the catalytic operating conditions on solid residue yields and other by-products formation.

Therefore, the aim of this study is to develop response surface models of the solid residue and aqueous product yields, during the microwave-assisted hydrolysis of poplar wood with sulphuric acid, by modelling process variables $(\mathrm{T}$,
$\mathrm{C}_{\mathrm{H} 2 \mathrm{so} 4}$ and $\mathrm{t}$ ). This study will expand upon existing knowledge of by-product yields for the development of integrated biorefinery solutions, as well as characterise and discuss applications of the solid residue.

\section{Materials and methods}

\section{Sample preparation and characterisation}

Poplar sawdust from a local short rotation coppice in the United Kingdom was dried and reduced to fine powder with a ball mill to less than $1 \mathrm{~mm}$ (Retsch, ZM500). The water-soluble extractives were determined using a solvent extractor (Dionex, ASE 350) with demineralised water according to NREL/TP-510-42619. Structural sugar analysis was conducted according to NREL/TP-510-42618 (Sluiter et al. 2012) and the sugar hydrolysate was analysed using an ICS-3000 Ion-Chromatography (Dionex, USA). The obtained compositions (on an oven-dry basis wt \%) from poplar sawdust were $2.16 \% \pm 0.05$ ash, $4.18 \% \pm 0.01$ water extractives, $25.05 \% \pm 0.66$ Klason lignin, $41.97 \% \pm 0.77$ cellulose (glucan), $11.47 \% \pm 0.43$ mannose, and $7.22 \% \pm 0.41$ hemicelluloses.

The reactions were conducted in an aqueous medium (deionised water) with varying concentrations of sulphuric acid (Sigma-Aldrich) as the homogeneous acid catalyst. Internal HPLC standards were prepared with analytical grade glucose, formic acid, acetic acid, levulinic acid and furfural (Sigma-Aldrich).

\section{Experimental setup}

The reactions were conducted using $30 \mathrm{ml}$ borosilicate reactors and heated with a Monowave 300 microwave reactor operating at $2.45 \mathrm{GHz}$ (Anton-Parr, Austria). In each experiment, $0.1 \mathrm{~g}$ of polar wood was mixed with $6 \mathrm{ml}$ of sulphuric acid solution and heated to the desired temperature within $2 \mathrm{~min}$, with an internal magnetic stirrer speed of $600 \mathrm{rpm}$. Post-reaction, the solids were separated using vacuum filtration with pre-dried and pre-weighed $2 \mu \mathrm{m}$ filter papers before sampling the liquid fraction. The liquid fraction was further filtered with a $0.2 \mu \mathrm{m}$ micro-filter before HPLC analysis. The reaction vessel was then washed with $500 \mathrm{ml}$ of deionised water to recover all the solids as well as to wash the acid out of the filter paper. The residue and filter paper were then dried at $60{ }^{\circ} \mathrm{C}$ for $24 \mathrm{~h}$ under vacuum and the dry solid weight was calculated.

\section{Analytical methods}

The post-reaction solutions were analysed using a HP1100 HPLC (Agilent, USA) with an Agilent 1200 Refractive 
Index Detector (RID) (Agilent, USA) equipped with a Aminex HPX-87H organic acids column (Bio-Rad, USA). The column and RID temperatures were maintained at $55^{\circ} \mathrm{C}$ and $5 \mathrm{mM} \mathrm{H}_{2} \mathrm{SO}_{4}$ eluent was used as the mobile phase with the flowrate maintained at $0.6 \mathrm{ml} / \mathrm{min}$. The weight percentage yields of product yields were calculated on a dry poplar feedstock basis using Eq. (1):

$Y_{\text {product }}=\frac{\text { Product produced }(g)}{\text { Dry mass of poplar wood reactant }(g)} \times 100$.

The theoretical levulinic acid yield was calculated on C6 sugar basis (glucose and mannose). The net formic acid yield was calculated by considering a stoichiometric formation of 1:1 molar levulinic to formic acid yield, with observed formic acid yield. As per Eq 2:

$Y_{\text {Net formic acid }}=Y_{\text {Formic acid }}-Y_{\text {Levuulinic acid }} \times 46.06 / 116.11$,

where $\mathrm{Mr}$ of levulinic acid $=116.11 \mathrm{~g} / \mathrm{mol}$ and $\mathrm{Mr}$ of formic acid $=46.06 \mathrm{~g} / \mathrm{mol}$.

\section{Solid residue characterisation}

The solid residue was analysed using a Vario MacroCube CHNS analyser (Elementar, Germany) and the oxygen was calculated by difference. The HHV was estimated using Eq. 3, where C, H, S, O, A represent the weight percentages of carbon, hydrogen, sulphur, oxygen and ash of the sample, respectively (Channiwala and Parikh 2002). X-ray fluorescence spectrometry (XRF) energy was conducted using a Rigaku NEX-CG (Rigaku, USA) for determination of selected trace elements. For each sample, two IR spectra were recorded and averaged using 16 scans with a resolution of $4 \mathrm{~cm}^{-1}$ (Spectrum Two, Perkin-Elmer, USA). The morphology and structure of the solid residue were evaluated with a Supra 40VP-FEG Surface Electron Microscope (Zeiss, Germany).

$$
\begin{aligned}
\mathrm{HHV}_{\text {predicted }}\left(\mathrm{MJ} \mathrm{kg}^{-1}=0.3491(\mathrm{C})+1.1783(\mathrm{H})\right. \\
+0.1005(\mathrm{~N})-0.1034(\mathrm{O})-0.0015(\mathrm{~A}))
\end{aligned}
$$

\section{Experimental design}

Response surface methodology (RSM) was used to investigate the effects of three independent variables (A: temperature/ ${ }^{\circ} \mathrm{C}$, B: time/minutes, $\mathrm{C}$ : conc. $\left.\mathrm{H}_{2} \mathrm{SO}_{4} / \mathrm{M}\right)$ on the yields of levulinic acid, furfural, solid residues, formic acid and acetic acid. RSM utilises mathematical and statistical techniques for modelling, interpreting and predicting one or more responses " $y$ " of interest to several input variables " $\chi$ " (from level i to j). Ideal reaction conditions can be retrieved
Table 1 Levels of the independent variables

\begin{tabular}{llllr}
\hline Independent variable & \multirow{2}{*}{ Unit } & \multicolumn{3}{l}{ Variable ranges } \\
\cline { 3 - 5 } & & Low & Medium & High \\
\hline Temperature & ${ }^{\circ} \mathrm{C}$ & 160 & 180 & 200 \\
Time & Min & 30 & 90 & 150 \\
$\mathrm{H}_{2} \mathrm{SO}_{4}$ concentration & M & 0.1 & 1.05 & 2 \\
\hline
\end{tabular}

from the model by fitting data from each experimental set into a second-order polynomial model as per Eq. (4):

$Y=\beta_{0}+\sum_{i=1}^{n} \beta_{i} X_{i}+\sum_{i=1}^{n} \beta_{i i} X_{i}^{2}+\sum_{i}^{n} \sum_{j>1}^{n} \beta_{i j} X_{i} X_{j}$,

where $Y$ is the predicted response, $\beta_{0}, \beta_{i}, \beta_{i i}$ and $\beta_{i j}$ are regression coefficients and $\mathrm{n}$ is the number of the experiments conducted. The sequential $F$ test, lack-of-fit test and other adequacy measures were used in selecting the best models. The graphical representation and mathematical investigation of the models were assessed for statistical importance using analysis of variance (ANOVA) with an interval of confidence $\alpha=0.1$ applied to estimate the significance of the model and each of the model terms (Prob. $F<p$ value). All statistical analyses were conducted using Design Expert version 11.0 (Stat-Ease Inc., Minneapolis, USA).

A three-level Box-Behnken experimental design was employed in this study requiring 17 runs or experimental data points, which included five replicates at the central point to estimate the model variance. The levels of the three variables are shown in Table 1 and the full experimental design, including order randomisation, is shown in Supplementary Table 1 . The run order was randomised and the non-central point values were replicated in triplicate.

\section{Results and discussion}

\section{Green chemical and solid product yields}

The response surfaces included in the following subsections were generated from statistically significant models (ANOVA tables provided in the Supplementary datasheet) for estimating the platform chemical yields with a reduced data set. The yield of each building block via the methods described in "Analytical methods" is shown in Table 2 and will be referred to in the hereafter subsections for focussed discussion.

\section{Levulinic acid yields}

The poplar wood was subjected to acid hydrolysis with sulphuric acid according to the Box-Behnken experimental 


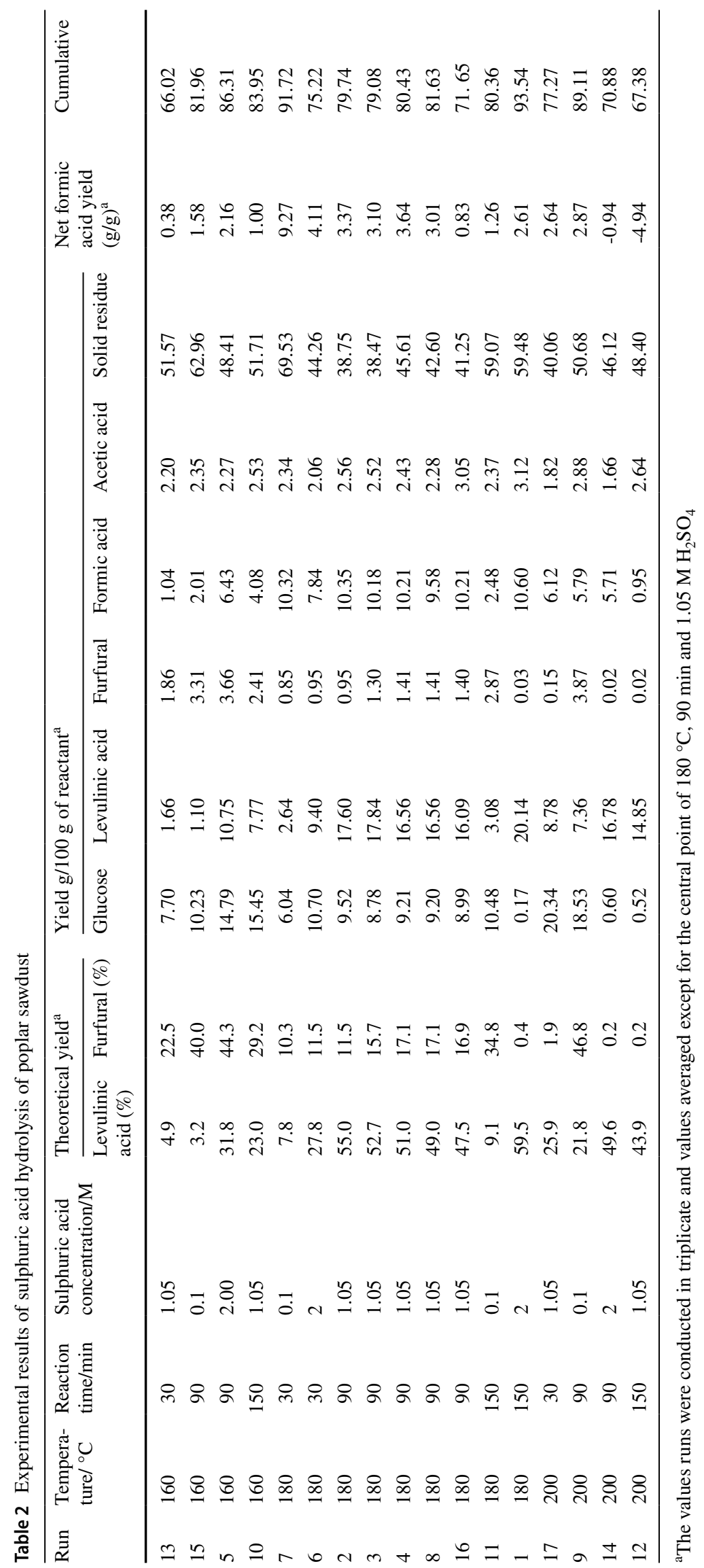



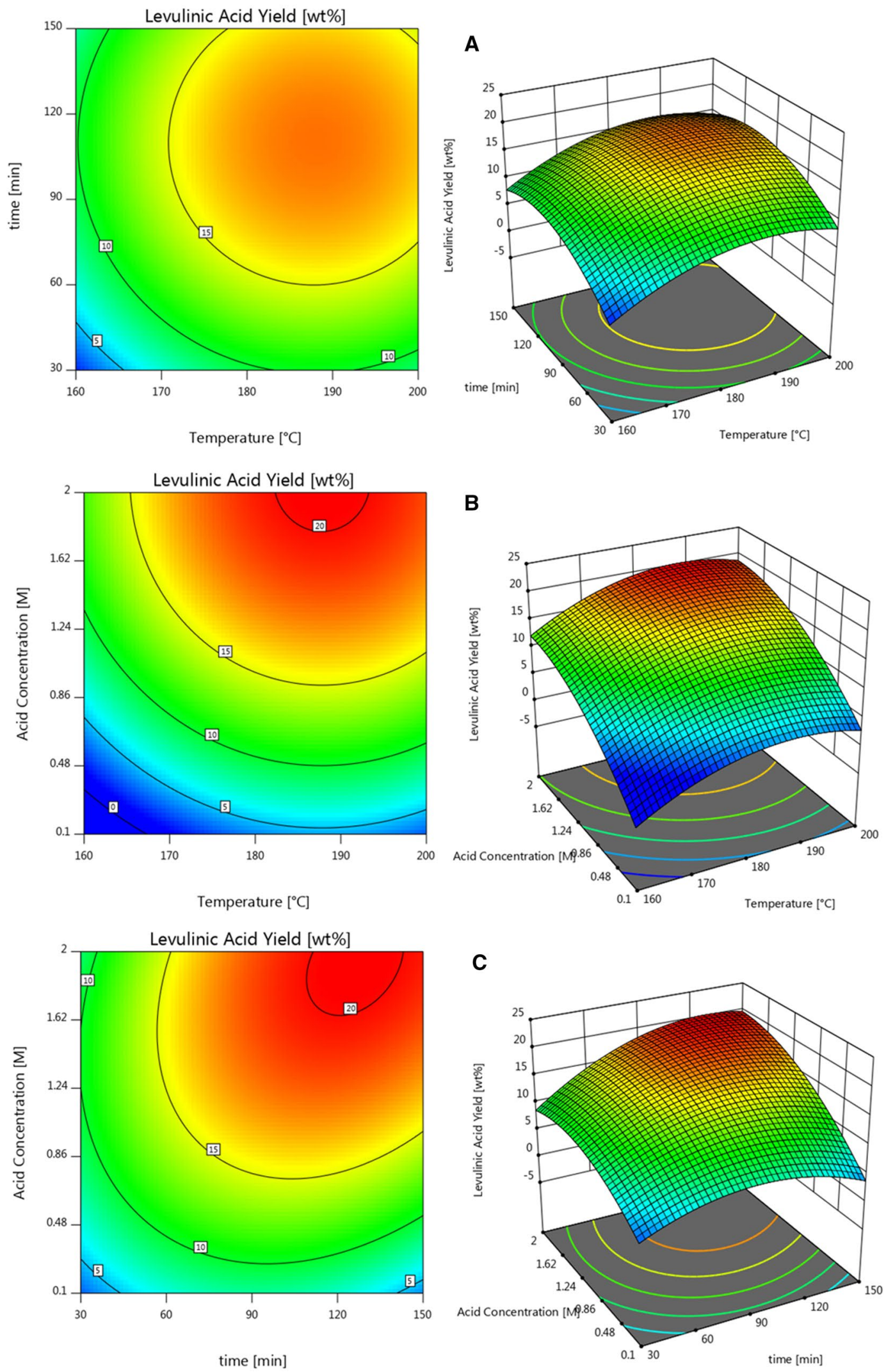

Fig. 1 3D response surface plots and 2D contour plots of levulinic acid yield (wt \%) with (a) varying temperature and time; (b) varying sulphuric acid concentration and temperature; (c) varying time and sulphuric acid concentration 

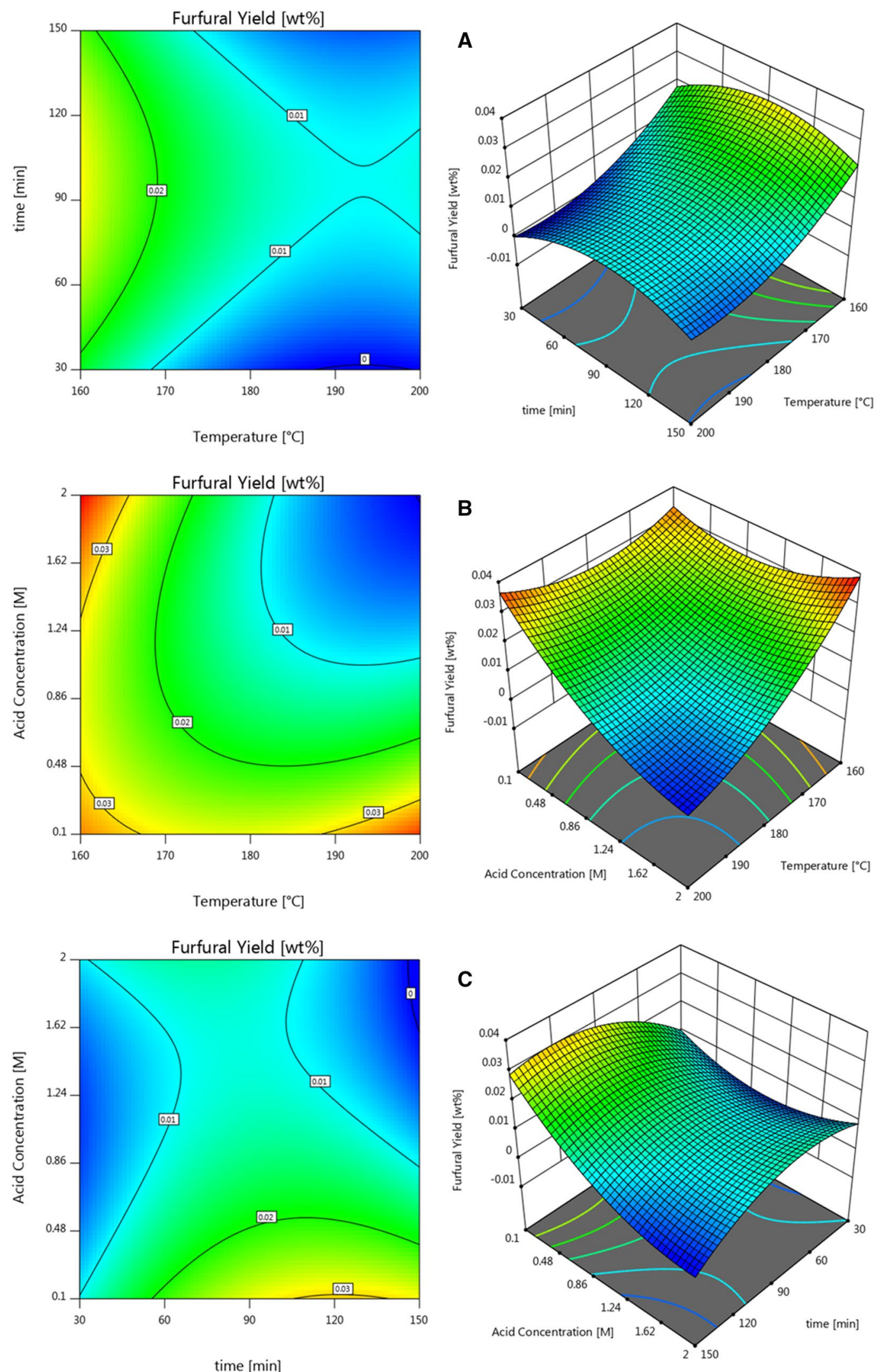

Fig. 2 3D response surface plots and 2D contour plots of furfural yield (wt \%) with (a) varying temperature and time; (b) varying sulphuric acid concentration and temperature; (c) varying time and sulphuric acid concentration 
design shown in Table 1 and all the results of all measured compounds are shown in Table 2 . The highest observed theoretical levulinic acid was $59.5 \%$ for poplar wood at $180{ }^{\circ} \mathrm{C}$, 150 min and $2 \mathrm{M}$ sulphuric acid (Run 1) that corresponds to a levulinic acid yield of $20.1 \mathrm{wt} \%$ of the initial biomass. The yields are in line with those from other lignocellulosic feedstocks such as wheat straw, pine chips and miscanthus that have been reported to be between 50 and $70 \%$ (Kang et al. 2018; Kłosowski et al. 2019). While the theoretical yield is more appropriate for discussing the catalysis process effect on the maximum stoichiometric yields achievable, the absolute weight yield evaluates the economic implications of both the technology and feedstocks, therefore both solid and theoretical yields will be discussed. The high C6 sugar content of the feedstock has resulted in levulinic acid yields exceeding $20 \mathrm{wt} \%$, which justifies the choice of polar wood as feedstock. However, the maximum yields were found at unusually long reaction times for microwave technology (150 min), which could be attributed to the recalcitrance of woody biomass and moderate reaction temperature $\left(180^{\circ} \mathrm{C}\right)$. This result indicates that the advantages of microwaveassisted heating are less pronounced when using recalcitrant biomass types.

The conversion of polar wood to levulinic acid was optimised using RSM and was modelled using analysis of variance (ANOVA) to produce a quadratic model, as shown in Eq. 4. The proposed model was statistically significant with an adj. $R^{2}=98 \%$ and a lack of fit of 0.44 , as shown in Supplementary Table 2 . The highest predicted theoretical levulinic acid yield was $62.1 \%$ or $21.0 \mathrm{wt} \%$, at $188{ }^{\circ} \mathrm{C}, 126 \mathrm{~min}$ and $1.93 \mathrm{M}$ sulphuric acid, which is higher than other works with untreated poplar wood, i.e. $52 \%$ with $\mathrm{HCl}$ (Galletti et al. 2012) and $49 \%$ with $\mathrm{H}_{2} \mathrm{SO}_{4}$ (Runge and Zhang 2012). The results of this study further highlight the potential of poplar wood as feedstock for levulinic acid production in a biorefinery context.

$$
\begin{aligned}
Y_{\mathrm{LA}}= & -3.77+0.0398 \mathrm{~T}+0.00223 \mathrm{t}+0.102 \mathrm{C}_{\mathrm{H}_{2} \mathrm{SO}_{4}} \\
& +0.000452 \mathrm{t} \times \mathrm{C}_{\mathrm{H}_{2} \mathrm{SO}_{4}}-0.00106 \mathrm{~T}^{2} \\
& -0.0000123 \mathrm{t}^{2}-0.0409 \mathrm{C}_{\mathrm{H}_{2} \mathrm{SO}_{4}}^{2}
\end{aligned}
$$

The 3D contour graphs in Fig. 1 show the performance of levulinic acid yield, according to Eq. 5, in relation to the three process variables. The sulphuric acid concentration had the highest impact on the levulinic acid yield, according to $1 \mathrm{~b}$ and $1 \mathrm{c}$. Low concentrations of $\mathrm{H}_{2} \mathrm{SO}_{4}(0.1 \mathrm{M})$ appear not to be sufficient to fully catalyse either the cellulose degradation or further conversion to levulinic acid, as shown by the high concentrations of glucose and solid residue, as shown in Runs 9,11 and 15. There was a slight decrease in levulinic acid yields at higher acid concentrations in correlation with acid-catalysed humin formation, as shown in Fig. 1c and d. Similarly, a decrease of levulinic acid yield can be observed at higher temperatures and longer times, indicating that levulinic acid degradation is occurring. It can therefore be concluded that interdependence of the three process variables shows that the highest levulinic acid yield can only be determined by co-optimization.

\section{Furfural yields}

Furfural yields were modelled using a modified ANOVA model, with an adj $\mathrm{R}^{2}$ of $95.8 \%$ (Supplementary Table 3) and the RSM plots are shown in Fig. 2. The overall furfural yields were lower than expected and decreased significantly with increasing temperature and sulphuric acid concentration, as seen in Fig. 2b. The speed at which the furfural degraded was unexpected with the optimum furfural conditions, according to Eq. 6, being $160^{\circ} \mathrm{C}, 71 \mathrm{~min}$ and $2 \mathrm{M}$ $\mathrm{H}_{2} \mathrm{SO}_{-}$which results in theoretical furfural and levulinic acid yield of $15.1 \%$ and $26.3 \%$, respectively. The highest furfural yield had a correspondingly low levulinic acid yield, which suggests that the hemi-cellulose solubilisation and subsequent transformation to furfural is significantly faster than cellulose to levulinic acid (Hendriks and Zeeman 2009). Furfural can degrade under the same conditions that are formed and can degrade into a multitude of products including formic acid and solid residues (Danon et al. 2013). The difference in reaction rates makes co-optimization of the two products difficult and the production of levulinic acid should be prioritised due to its higher potential yield.

There was a small increase in furfural yields with reaction time, peaking at approximately $90 \mathrm{~min}$, following which a sharp decrease in furfural yield was observed. It should be noted that the rapid decrease in furfural yields corresponds to a significant increase in solids yield, as shown in Fig. 3. Furfural decomposition and polymerisation towards humins has been reported under acidic conditions (Sairanen et al. 2014; Dussan et al. 2016). Moreover, Runge and Zhang (2012) proposed that the degradation of furfural caused the formation of tar-like humin structures, inhibiting cellulose hydrolysis. Therefore, the solid residue yields can be partially attributed to furfural degradation and the conversion of furfural to solid residue could be an interesting optimisation feature in future works, if solid residues can be valorised and low furfural concentrations do not warrant separation cost.

$$
\begin{aligned}
Y_{\mathrm{FF}}= & +0.5204-0.00596 \mathrm{~T}+0.000598 \mathrm{t}+0.0858 \mathrm{C}_{\mathrm{H}_{2} \mathrm{SO}_{4}} \\
& -0.000554 \mathrm{~T} \times \mathrm{C}_{\mathrm{H}_{2} \mathrm{SO}_{4}}-0.000129 \mathrm{t} \times \mathrm{C}_{\mathrm{H}_{2} \mathrm{SO}_{4}} \\
& -0.0000169 \mathrm{~T}^{2}-2.391 \times 10^{-3} \mathrm{t}^{2}+0.00823 \mathrm{C}_{\mathrm{H}_{2} \mathrm{SO}_{4}}^{2}
\end{aligned}
$$



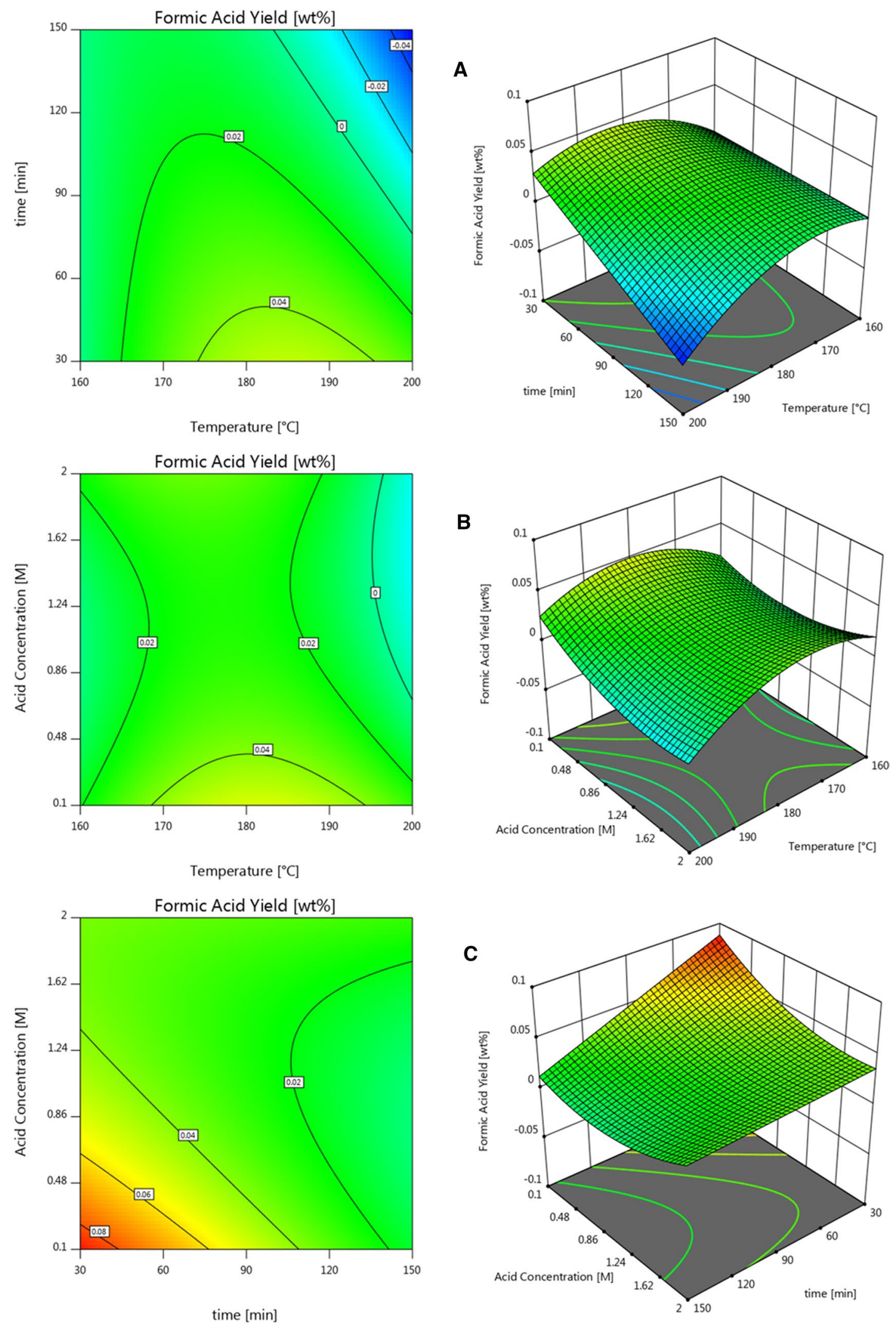

Fig. 3 3D response surface plots and 2D contour plots of net formic acid yield (wt \%) with (a) varying temperature and time; (b) varying sulphuric acid concentration and temperature; (c) varying time and sulphuric acid concentration 


\section{Net formic acid}

Formic acid was expected to primarily come as a stoichiometric by-product of levulinic acid formation (Shen and Wyman 2011). However, the formic-to-levulinic acid ratio was never stoichiometric in this study and a discrepancy has also been reported in other works, which has attributed to the degradation of sugars among other side reactions (Swift et al. 2014; Flannelly et al. 2016). An understanding of the side reactions could be provided by excluding the formic acid produced from levulinic acid, though it should be noted that the formic acid from decomposed levulinic acid is not accounted for in this model and will overestimate the net formic acid formation at higher conditions. The RSM model developed shows that net formic can modelled to a high level of significance, represented by an adjusted $R^{2}$ of $90.64 \%$ and a lack-of-fit test of 0.896 (Supplementary Table 4).

The highest observed net formic acid yield of $+9.4 \mathrm{wt} \%$ was recorded at $180{ }^{\circ} \mathrm{C}, 30 \mathrm{~min}$ and $0.1 \mathrm{M} \mathrm{H}_{2} \mathrm{SO}_{4}$, which indicates that an initially large $9.4 \mathrm{wt} \%$ of the poplar wood was converted to formic acid, possibly from the fast hydrolysis of hemi-cellulose and degradation of sugars. Formic acid formed in this manner should remain constant at higher temperatures and reaction times. It was therefore unexpected to observe an overall trend of decreasing formic acid with higher reaction time and temperature. The overall trends and negative net yields of formic acid of $-0.9 \mathrm{wt} \%$ and -4.9 wt $\%$ were recorded at $200{ }^{\circ} \mathrm{C}, 90 \mathrm{~min}, 2 \mathrm{M}$ and $180{ }^{\circ} \mathrm{C}$, $150 \mathrm{~min}$ and $1.05 \mathrm{M}$, indicating that formic acid is consumed in a side reaction. Formic acid has been found to be stable under similar conditions with monomeric sugars, suggesting that such consumption is linked to the lignocellulose feedstock (Flannelly et al. 2016; Qi et al. 2016). Lignin has been observed to decrease formic acid yields during acid hydrolysis (Yoon et al. 2014) and could be attributed to the formylation of lignin under microwave heating (Wang et al. 2017). It is possible that consumption of formic acid is linked with the solid residue formation, however, this aspect was not further investigated.

\section{Acetic acid}

Attempts were made at modelling the formation of acetic acid using ANOVA with no success in identifying a correlation of significance. The acetic acid appears to be relatively constant in the range of $2.43 \mathrm{wt} \% \pm 0.30 \mathrm{wt} \%$ across most conditions. The highest and the lowest yields were $3.12 \%$ $\left(180{ }^{\circ} \mathrm{C}, 150 \mathrm{~min}, 2 \mathrm{M}\right)$ and $1.66 \%\left(200{ }^{\circ} \mathrm{C}, 90 \min 2 \mathrm{M}\right)$, respectively. These outliers may suggest that minor reactions are occurring. The consistent yield across all parameters indicates the acetic acid was mostly present in the unreacted biomass and is easily solubilised (Gong et al. 2019). This seems to indicate that acetic acid yields are not significantly affected by the reaction parameters, but are rather inherent to feedstock composition.

\section{Residual solids yields}

The post-reaction solid residues were expected to contain the products of several distinct reactions including cellulose hydrolysis and humin formation. Though kinetic models would offer greater insight into optimization and reactor design, they require detailed reaction models that simply do not exist for all solids' formation mechanisms. Despite this, it was possible to achieve a highly significant model (adj $R^{2}$ of $93.61 \%$ ), with lack of fit being insignificant ( $p=0.94)$, as shown in the Supplementary Table 4 . The RSM model is, therefore, shown to be an appropriate tool for modelling the solid yields under catalytic conditions without the need for detailed of models as shown by the high $R^{2}$.

The lowest observed solids yield was $40.0 \mathrm{wt} \%$ at $200^{\circ} \mathrm{C}$, $30 \mathrm{~min}$ and $1.05 \mathrm{M} \mathrm{H}_{2} \mathrm{SO}_{4}$ (Run 17), which corresponded with observed theoretical levulinic acid yield of $25.9 \%$. The low levulinic acid yield was associated with glucose yields of $20.1 \mathrm{wt} \%$, indicating substantial cellulose hydrolysis without sufficient time for the conversion of glucose into levulinic acid. The low solids yield was still in excess of the lignin content of poplar wood (25 wt \%) and can be further minimised, using Eq. 7, to $36.6 \mathrm{wt} \%$ (theoretical levulinic acid yield of $52.3 \mathrm{wt} \%$ ) at the conditions of $200{ }^{\circ} \mathrm{C}$, $64 \mathrm{~min}$ and $1.31 \mathrm{M} \mathrm{H}_{2} \mathrm{SO}_{4}$. These low solids yields can be attributed to the hydrolysis of the cellulose and hemicellulose, after which solid residue yield will be affected by addition of condensed materials. In fact, from Fig. $4 \mathrm{a}$, it can be seen that high temperature and short reaction time appear to facilitate sufficient biomass solubilisation without causing significant solids formation. The second lowest solids yield of $41.3 \mathrm{wt} \%{ }^{1}$ and $50.6 \%$ theoretical levulinic acid yield at $180{ }^{\circ} \mathrm{C}, 90 \mathrm{~min}$ and $1.05 \mathrm{M} \mathrm{H}_{2} \mathrm{SO}_{-}$shows that the process parameters can be optimised to increase levulinic acid yields with minimal effect on the solid residue yields. There was also a decrease in the solids yield between the highest actual and predicted levulinic acid yields (20.1 wt \% and 20.9 wt \%), which corresponded with solids yields of $59.2 \%$ and $52.1 \%$, respectively. The decrease in solids yield with levulinic acid optimisation is most likely caused by the reduction in competitive humin formation reactions, which shows a possible synergy between levulinic acid maximisation alongside solids minimisation.

\footnotetext{
1 The conditions of $180{ }^{\circ} \mathrm{C}, 90 \mathrm{~min}$ and $1.05 \mathrm{M} \mathrm{H}_{2} \mathrm{SO}_{4}$ are recorded five times in Table 2 as part of the RSM methodology to estimate variance and stated values are the average value.
} 

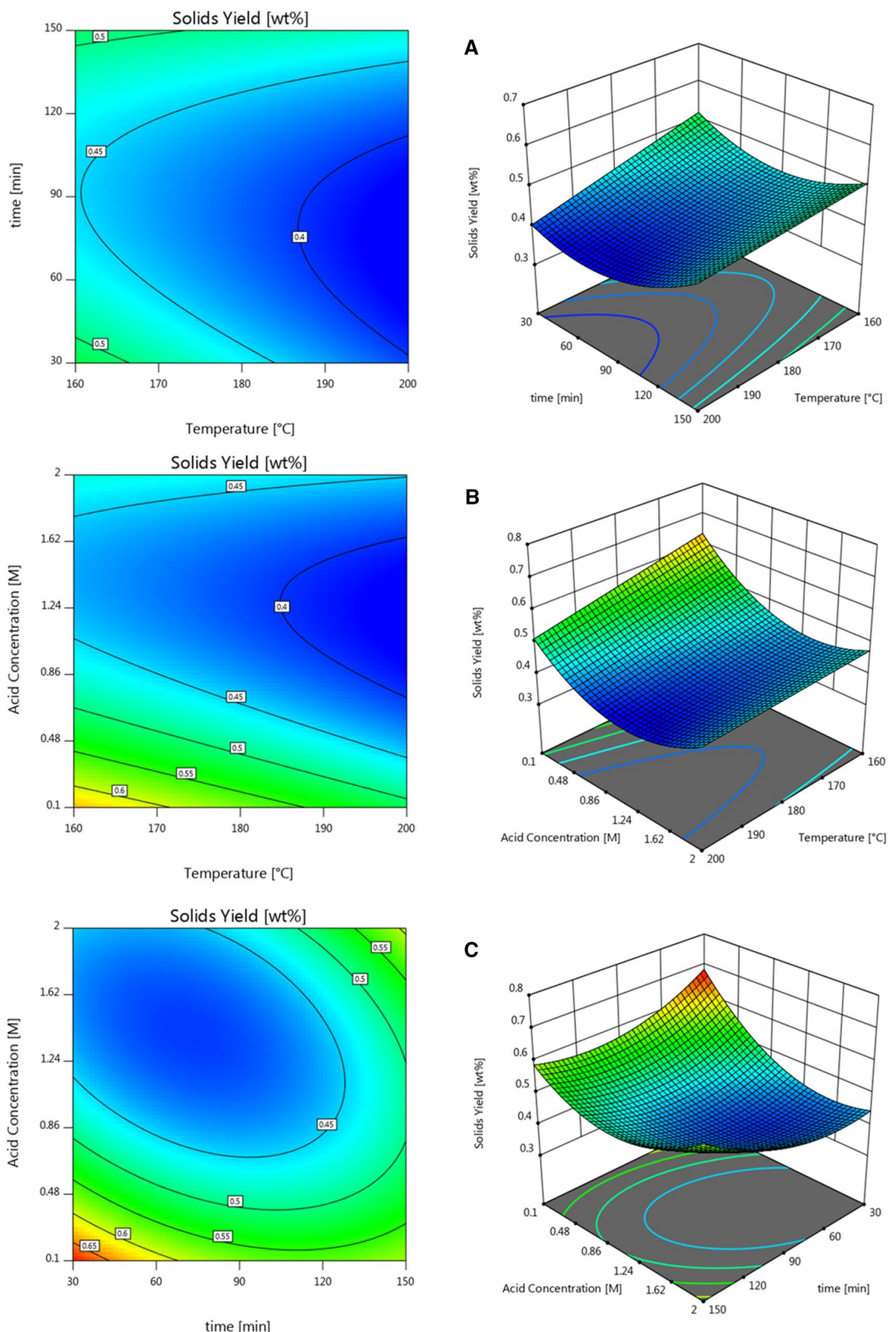

Fig. 4 3D response surface plots and 2D contour plots of solid residue yield (wt \%) with (a) varying temperature and time; (b) varying sulphuric acid concentration and temperature; (c) varying time and sulphuric acid concentration 
Table 3 Elemental composition of solid residues and poplar wood on a dry weight basis

\begin{tabular}{llcc}
\hline & Poplar Wood & $\begin{array}{l}\text { Lowest } \\
\text { solids } \\
\text { yield }\end{array}$ & $\begin{array}{l}\text { Highest } \\
\text { levulinic acid } \\
\text { yield }\end{array}$ \\
\hline Solid residue yield (wt \%) & - & 40.06 & 59.48 \\
$\mathrm{C}(\mathrm{wt} \%)$ & 51.18 & 60.37 & 62.12 \\
$\mathrm{H}(\mathrm{wt} \%)$ & 6.28 & 5.37 & 5.33 \\
$\mathrm{~N}(\mathrm{wt} \%)$ & 0.11 & 0.08 & 0.16 \\
$\mathrm{~S}(\mathrm{wt} \%)$ & 0.06 & 0.07 & 0.12 \\
$\mathrm{O}(\mathrm{wt} \%)^{\mathrm{a}}$ & 42.22 & 32.46 & 30.84 \\
$\mathrm{Ash}(\mathrm{wt} \%)$ & 2.16 & 1.64 & 1.45 \\
$\mathrm{HHV}$ & 24.6 & 27.8 & 27.6 \\
$\mathrm{H} / \mathrm{C}$ & 1.47 & 1.07 & 1.03 \\
$\mathrm{O} / \mathrm{C}$ & 0.62 & 0.40 & 0.37 \\
$\mathrm{C} / \mathrm{N}$ & $755 / \mathrm{kg})^{\mathrm{b}}$ & 20.8 & 388 \\
$\mathrm{Mg}(\mathrm{mg} / \mathrm{kg})$ & 465 & 28.1 & 29.3 \\
$\mathrm{Al}(\mathrm{mg} / \mathrm{kg})$ & 224 & 41.2 & 41.6 \\
$\mathrm{Si}(\mathrm{mg} / \mathrm{kg})$ & 71 & 4.3 & 1.4 \\
$\mathrm{P}(\mathrm{mg} / \mathrm{kg})$ & 52.9 & 16.8 & 13.6 \\
$\mathrm{Cl}(\mathrm{mg} / \mathrm{kg})$ & 18.1 & 45.6 & 4.3 \\
$\mathrm{~K}(\mathrm{mg} / \mathrm{kg})$ & 11.3 & 20.7 & 10.9 \\
$\mathrm{Ca}(\mathrm{mg} / \mathrm{kg})$ & 258 & 2.5 & 3.4 \\
$\mathrm{Fe}(\mathrm{mg} / \mathrm{kg})$ & 525 & 0.6 & 0.5 \\
$\mathrm{Cu}(\mathrm{mg} / \mathrm{kg})$ & 6.4 & 2.6 & 1.0 \\
$\mathrm{Zn}(\mathrm{mg} / \mathrm{kg})$ & 2.2 & & \\
\hline $\mathrm{Ca}$ & 5.4 & & \\
\hline
\end{tabular}

${ }^{\mathrm{a}}$ Calculated by difference

${ }^{\text {b}}$ Calculated using Eq. 3

$$
\begin{aligned}
Y_{\text {solids }}= & 1.682-0.0475 \mathrm{~T}-0.00715 \mathrm{t}-0.639 \mathrm{C}_{\mathrm{H}_{2} \mathrm{SO}_{4}} \\
& +0.0000171 \mathrm{~T} \times \mathrm{t}+0.00131 \mathrm{~T} \times \mathrm{C}_{\mathrm{H}_{2} \mathrm{SO}_{4}} \\
& -0.00113 \mathrm{t} \times \mathrm{C}_{\mathrm{H}_{2} \mathrm{SO}_{4}}-0.0000176 \mathrm{t}^{2}+0.116 \mathrm{C}_{\mathrm{H}_{2} \mathrm{SO}_{4}}^{2}
\end{aligned}
$$

The acid concentration had a significant effect on the solid yields, as shown in Fig. 4b and c, by regulating both the solubilisation of the biomass as well as the formation of solid residues, which implies that the solids formation from lignocellulosic biomass is primarily acid catalysed. The moderate effect of temperature on the solids yield, as shown in Fig. 4a and b, suggests that the formation of solids is reactant limited, meaning that solids could be minimised by utilising high-temperature reactors in conjunction with low residence time. The solid residue yield significantly increased from $38.5 \mathrm{wt} \%$ to $57.5 \mathrm{wt} \%$ between 90 and $150 \mathrm{~min}$ at $180{ }^{\circ} \mathrm{C}$. This $20 \mathrm{wt} \%$ increase in solids yield over $60 \mathrm{~min}$ indicates a large solids forming reaction process or system. The reduction in levulinic acid, formic acid and furfural over that time does not fully explain the increase in solids weight. This can only be partially attributed to the acid-catalysed formation of humins by cross-polymerisation of 5-HMF and dehydration by-products (Patil and Lund 2011; Patil et al. 2012; Zandvoort et al. 2015). The cross-polymerisation of sugars and intermediaries can be further catalysed by phenolic compounds similar to lignin (Ryu et al. 2010), but would not fully explain the dramatic increase in yield after $90 \mathrm{~min}$. Acid-soluble lignin is a significant fraction of biomass that was not measured in this
Fig. 5 SEM images of solid residues produced from different reaction conditions: lowest solids yield (a) and highest levulinic acid yield (b)

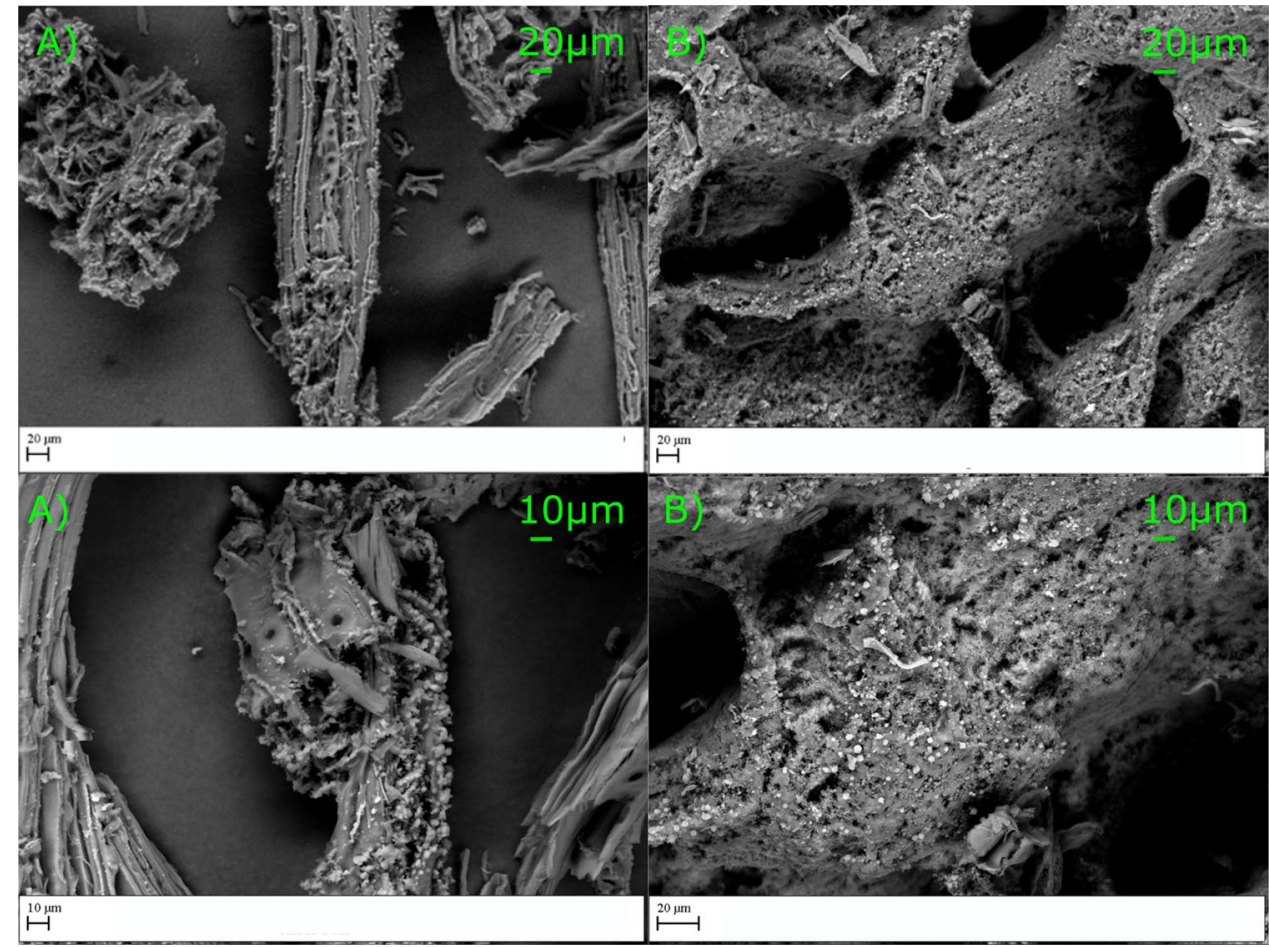


Fig. 6 FTIR spectra of poplar wood (a), lowest solid residue (b), highest levulinic acid yield (c)

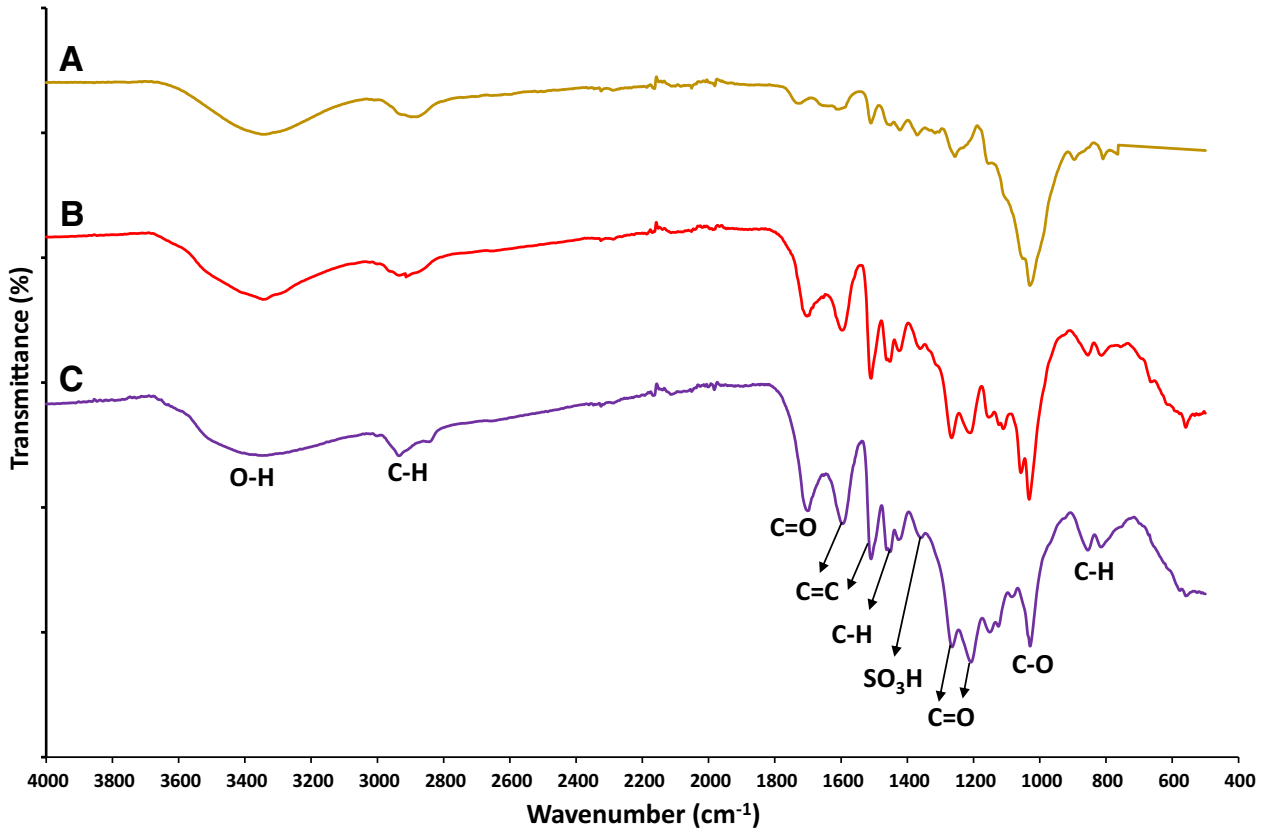

study. However, previous studies have reported condensation of acid-soluble lignin with reactive intermediaries and sugars (Matsushita et al. 2004; Dussan et al. 2016). To fully understand the process of solid residue formation from lignocellulosic material, analysis and measurement of all aqueous by-products would be required.

Furthermore a notable excess of gas formation at higher temperatures $\left(200{ }^{\circ} \mathrm{C}\right)$ was observed, that could not be explained by gas expansion alone. Although the amount of gas formed could not be measured accurately, the formation of gas would potentially indicate hydrothermal carbonization (HTC) is taking place (Nizamuddin et al. 2018). HTC has been reported under sub-critical conditions for cellulose and lignin at $180-200{ }^{\circ} \mathrm{C}($ Heidari et al. 2018). There are similarities between the catalytic formation of humins and biomass, with regard to polymerisation mechanisms and especially the role of 5-HMF (Zandvoort et al. 2013; Lei and Tian 2016). A study by Guiotoku on hydrothermal carbonization of pine sawdust at $200{ }^{\circ} \mathrm{C}$ with citric acid found a similar increase with reaction time (35-45\% increase between 60 and $240 \mathrm{~min}$ ) (Guiotoku et al. 2009). Guiotoku attributed the increase in solids to the reaction of volatile compounds with lignin and observed deposition with SEM. This potentially could resemble catalytic humin growth and further study in this area is needed to elucidate some of the more complex reactions in both processes.

Under all reaction conditions, the solid residue yield exceeded that of levulinic acid despite the solids typically being considered a waste product. The solid residues should, therefore, be considered a distinct by-product that warrants further analysis. It would be desirable to either minimise solid residue yields or modify the characteristic properties of the solids for commercial applications, as the disposal of the solid residue would be of significant cost for future biorefineries.

\section{Residues characterisation and their potential applications}

The solid residues corresponding to the lowest solids yield (200 ${ }^{\circ} \mathrm{C}, 30 \mathrm{~min}$ and $1.05 \mathrm{M} \mathrm{H}_{2} \mathrm{SO}_{4}$, Run 17) and highest levulinic acid yield $\left(180{ }^{\circ} \mathrm{C}, 150 \mathrm{~min}\right.$ and $2 \mathrm{M} \mathrm{H}_{2} \mathrm{SO}_{4}$, Run 1) were chosen for further characterisation alongside untreated poplar wood for comparison. The solid residue yields were quantified at $40 \mathrm{wt} \%$ and $59 \mathrm{wt} \%$, respectively. The solid residue elemental composition, identified by CHNSO and XRF analyses using the methods described in "Analytical methods", is reported in Table 3, which suggest similar chemical compositions despite differing reaction conditions. The decrease in $\mathrm{H} / \mathrm{C}$ and $\mathrm{O} / \mathrm{C}$ is indicative of dehydration reactions, which are associated with polysaccharide hydrolysis and humin formation (Zandvoort et al. 2015; Agarwal et al. 2017).

A significant increase in the carbon content from $51 \mathrm{wt} \%$ to $60-62$ wt $\%$ occurred during acid catalysis, with the solid residue forming carbon-rich chars. This is further evidenced by the minimal difference between the calculated HHV of the two samples $\left(28.2\right.$ and $\left.28.0 \mathrm{MJkg}^{-1}\right)$ in Table 3 , which indicates potential in the use of the solid residue as a fuel source. Therefore, the acid hydrolysis acts as an energy densification process in the form of solid residue (when compared with HHV of commercially available poplar wood as fuel), in addition to the production of high-value chemicals generated by this biorefining technique. Similar 
algae hydro-char, from the fast catalysis of red seaweed with sulphuric acid, found experimental higher heating values of 19-25 $\mathrm{MJ} \mathrm{kg}^{-1}$ (Cao et al. 2019). However, an increase in sulphur content, due to sulphuric acid catalyst, from 0.06 wt $\%$ to $0.07-0.12$ wt $\%$ can also be observed. This would require post-combustion flue gas treatment and must be accounted for in a biorefinery scenario, where solid residue is used for combustion.

Trace elements analysis via XRF shows a decrease in concentrations of $\mathrm{Mg}, \mathrm{Al}, \mathrm{Si}, \mathrm{P}, \mathrm{K}, \mathrm{Ca}, \mathrm{Fe}, \mathrm{Cu}$ and $\mathrm{Zn}$ due to leaching of these elements, as shown in Table 3 . It is well known that metals have increased mobility at low $\mathrm{pH}$ and the catalysis process has caused acid extraction of the biomass (Kröppl and Lanzerstorfer 2013), which may affect subsequent aqueous processes. The overall decrease in nutrients required for biological growth of microorganisms or soil amendment should also be noted, including a significant increase in the $\mathrm{C} / \mathrm{N}$ ratio. The untreated poplar wood was inherently low in nutrients and, as result, the solid residue would perform poorly as fertiliser. However, there may be opportunities in the use of the solid residue as a biochar for stimulating microbial proliferation in anaerobic digestion systems or for carbon sequestration purposes. The use of solid residue in biochar applications would require further investigation, but could potentially be used as a soil amendment for energy crops, as a way to create a closed loop production method.

The structural changes in the solid residue between the two settings can be visually seen in Fig. 5. The residue at the lowest solids yield, Fig. 5a, has a similar morphology to unreacted biomass, implying incomplete hydrolysis of the polysaccharide matrix. A honeycomb structure appears to have formed at the highest levulinic acid setting, Fig. 5b, with significant spherical humin formation covering most of the residues external surface. Carbonaceous spheres are also present on Fig. 5a, possibly linked with fast degradation of furfural. The carbonaceous spheres resemble those reported in other works, (Guiotoku et al. 2009; Qi et al. 2016) investigating humin growth from acid hydrolysis of lignocelluloses, confirming earlier discussions. Consequently, the increase in solid yields can be attributed to humin formation and can be controlled to modify the solid residue properties in the future.

The FTIR spectra of the solid residues and poplar wood are reported in Fig. 6 and show the structural changes that occurred during the acid hydrolytic process. The peaks at $3600-3000 \mathrm{~cm}^{-1}, 3000-2800 \mathrm{~cm}^{-1}$ and $1032 \mathrm{~cm}^{-1}$ are associated with $\mathrm{O}-\mathrm{H}$ stretching, $\mathrm{C}-\mathrm{H}$ bending and $\mathrm{C}-\mathrm{O}$ stretching, respectively, from cellulose and hemicellulose. The gradual decrease in these three peaks indicates the partial degradation of the polysaccharide structures, with residual cellulose persisting at longer reaction times. Other peaks can be attributed to a variety of functional groups such as: at $1700 \mathrm{~cm}^{-1}$ to $\mathrm{C}=\mathrm{O}$ stretching, at 1595 and $1510 \mathrm{~cm}^{-1}$ to aromatic $\mathrm{C}=\mathrm{C}$ stretching, finally at $1450 \mathrm{~cm}^{-1}$ to $\mathrm{C}-\mathrm{H}$ bending. Moreover, the peaks at 1260 and 1210 are attributed to C-O stretching, while peaks between 950 and $750 \mathrm{~cm}^{-1}$ are normally associated with aromatic $\mathrm{C}-\mathrm{H}$ bending. Interestingly, the peak around $1360 \mathrm{~cm}^{-1}$ can be linked to $\mathrm{SO}_{3} \mathrm{H}$ indicating sulfonation of the residue, which is in agreement with the elemental analysis findings. The functional groups present in the residue resemble lignin, hydrochars and humins (Patil et al. 2012; Tsilomelekis et al. 2016; Jaruwat et al. 2018). However, the increase in absorption spectra with regard to time is atypical for hydrothermal carbonisation and can be attributed to humin formation. This is also demonstrated by the increase in $\mathrm{C}=\mathrm{C}$ stretching at 1595 and $1510 \mathrm{~cm}^{-1}$, which indicates further aromatisation and furan formation earlier associated with humins. The formation of stable aromatic structures with greater biogeochemical recalcitrance can potentially be used as a biochar for carbon sequestration (Singh et al. 2016).

\section{Conclusion}

This study reports that the sulphuric acid-catalysed conversion of poplar wood into levulinic acid can be optimised through RSM methods, leading to yields of up to $21.0 \mathrm{wt} \%$. Results indicate the hemicellulose and furfural conversion rates were excessively rapid and do not allow co-optimization of alongside levulinic acid yield in a single-stage reactor. The solids yield varied significantly from 38 to $63 \mathrm{wt} \%$ and under all conditions, the solid residue yield exceeded that of levulinic acid. The solid residue was characterised and found to have potential use as a fuel or as biochar. This could be minimised by low reaction times and moderate acid conditions, however, further work is needed to understand the reaction mechanisms involved in the formation of solid residue from the acid hydrolysis of lignocellulosic materials. Formic acid was greatly affected by variation of reaction conditions as well as important side reactions that appear to affect the yields of other products. This work constitutes a useful starting point for further studies aiming to understand how side reaction mechanisms are affected by reaction variables, as this is critical for developing cost-effective lignocellulosic biorefineries. in the future.

Acknowledgements This research was supported by Manchester Metropolitan University via the Research Accelerator Award (RAG 2017/18-113380) in collaboration with Dr Jonas Gruber, Department of Analytical Chemistry at University of São Paulo, Brazil. BBSRC NIBB's network High Value from Plants funded the training and compositional analysis of biomass in conjunction with Celignis ltd. (CORE-TA-19). 


\section{Compliance with ethical standards}

Conflict of interest On behalf of all authors, the corresponding author states that there is no conflict of interest.

Open Access This article is licensed under a Creative Commons Attribution 4.0 International License, which permits use, sharing, adaptation, distribution and reproduction in any medium or format, as long as you give appropriate credit to the original author(s) and the source, provide a link to the Creative Commons licence, and indicate if changes were made.The images or other third party material in this article are included in the article's Creative Commons licence, unless indicated otherwise in a credit line to the material. If material is not included in the article's Creative Commons licence and your intended use is not permitted by statutory regulation or exceeds the permitted use, you will need to obtain permission directly from the copyright holder.To view a copy of this licence, visit http://creativecommons.org/licenses/by/4.0/.

\section{References}

Agarwal S, Van Es D, Jan H (2017) Catalytic pyrolysis of recalcitrant, insoluble humin byproducts from C6 sugar biorefineries. J Anal Appl Pyrolysis 123:134-143. https://doi.org/10.1016/j. jaap.2016.12.014

Cao L, Yu IKM, Cho DW et al (2019) Microwave-assisted low-temperature hydrothermal treatment of red seaweed (Gracilaria lemaneiformis) for production of levulinic acid and algae hydrochar. Bioresour Technol 273:251-258. https://doi.org/10.1016/j.biort ech.2018.11.013

Channiwala SA, Parikh PP (2002) A unified correlation for estimating HHV of solid, liquid and gaseous fuels. Fuel 81:1051-1063. https ://doi.org/10.1016/S0016-2361(01)00131-4

Chen SS, Yu IKM, Tsang DCW et al (2017) Valorization of cellulosic food waste into levulinic acid catalyzed by heterogeneous $\mathrm{Br} \emptyset$ nsted acids: temperature and solvent effects. Chem Eng J 327:328-335. https://doi.org/10.1016/j.cej.2017.06.108

Chen SS, Wang L, Yu IKM et al (2018) Valorization of lignocellulosic fibres of paper waste into levulinic acid using solid and aqueous Br Ønsted acid. Bioresour Technol 247:387-394. https://doi. org/10.1016/j.biortech.2017.09.110

Danon B, Van Der Aa L, De Jong W (2013) Furfural degradation in a dilute acidic and saline solution in the presence of glucose. Carbohydr Res 375:145-152. https://doi.org/10.1016/j.carre s.2013.04.030

Dussan K, Girisuta B, Haverty D et al (2013) Bioresource technology kinetics of levulinic acid and furfural production from Miscanthus Â giganteus. Bioresour Technol 149:216-224. https://doi. org/10.1016/j.biortech.2013.09.006

Dussan K, Girisuta B, Lopes M et al (2016) Effects of soluble lignin on the formic acid-catalyzed formation of furfural: a case study for the upgrading of hemicellulose. Chemsuschem 9:492-504. https ://doi.org/10.1002/cssc.201501415

Flannelly T, Lopes M, Kupiainen L, Dooley S, Leahy JJ (2016) Nonstoichiometric formation of formic and levulinic acids from the hydrolysis of biomass derived hexose carbohydrates. RSC Adv 6(7):5797-5804

Galletti AMR, Antonetti C, De Luise V et al (2012) Levulinic acid production from waste biomass. BioResources 7:1824-1834. https ://doi.org/10.15376/biores.7.2.1824-1835

Girisuta B, Janssen LP, Heeres HJ (2007) Kinetic study on the acidcatalyzed hydrolysis of cellulose to levulinic acid. Ind Eng Chem Res 46(6):1696-1708
Gong SH, Im HS, Um M et al (2019) Enhancement of waste biomass fuel properties by sequential leaching and wet torrefaction. Fuel 239:693-700. https://doi.org/10.1016/j.fuel.2018.11.069

Guiotoku M, Rambo CR, Hansel FA et al (2009) Microwave-assisted hydrothermal carbonization of lignocellulosic materials. Mater Lett 63:2707-2709. https://doi.org/10.1016/j.matlet.2009.09.049

Heidari M, Dutta A, Acharya B, Mahmud S (2018) A review of the current knowledge and challenges of hydrothermal carbonization for biomass conversion. J Energy Inst. https://doi.org/10.1016/j. joei.2018.12.003

Hendriks ATWM, Zeeman G (2009) Bioresource technology pretreatments to enhance the digestibility of lignocellulosic biomass. 100:10-18. https://doi.org/10.1016/j.biortech.2008.05.027

Jaruwat D, Udomsap P, Chollacoop N et al (2018) Effects of hydrothermal temperature and time of hydrochar from Cattail leaves. AIP Conf Proc. https://doi.org/10.1063/1.5053192

Kang S, Fu J, Zhang G (2018) From lignocellulosic biomass to levulinic acid: a review on acid-catalyzed hydrolysis. Renew Sustain Energy Rev 94:340-362. https://doi.org/10.1016/j. rser.2018.06.016

Kłosowski G, Mikulski D, Menka A (2019) Microwave-assisted onestep conversion of wood wastes into Levulinic acid. Catalysts 9:753. https://doi.org/10.3390/catal9090753

Kröppl M, Lanzerstorfer C (2013) Acidic extraction and precipitation of heavy metals from biomass incinerator cyclone fly ash. Web Conf 1:10-13. https://doi.org/10.1051/e3sconf/20130116007

Kumar R, Singh S, Singh OV (2008) Bioconversion of lignocellulosic biomass: biochemical and molecular perspectives. J Ind Microb Biotechnol 35(5):377-391

Lei Y, Su H, Tian R (2016) Morphology evolution, formation mechanism and adsorption properties of hydrochars prepared by hydrothermal carbonization of corn stalk. RSC Adv 6(109):107829107835. https://doi.org/10.1039/c6ra21607b

Matsushita Y, Kakehi A, Miyawaki S, Yasuda S (2004) Formation and chemical structures of acid-soluble lignin II: reaction of aromatic nuclei model compounds with xylan in the presence of a counterpart for condensation, and behavior of lignin model compounds with guaiacyl and syringyl nuclei in $72 \%$ sulfuric. J Wood Sci 50:136-141. https://doi.org/10.1007/s10086-003-0543-9

Melligan F, Dussan K, Auccaise R et al (2012) Bioresource technology characterisation of the products from pyrolysis of residues after acid hydrolysis of Miscanthus. Bioresour Technol 108:258-263. https://doi.org/10.1016/j.biortech.2011.12.110

Mija A, van der Waal JC, Pin JM, Guigo N, de Jong E (2017) Humins as promising material for producing sustainable carbohydratederived building materials. Constr Build Mater 15(139):594-601

Moriarty K, Milbrandt A, Warner E, et al (2016) 2016 Bioenergy Industry Status Report

Mukherjee A, Dumont MJ, Raghavan V (2015) Review: sustainable production of hydroxymethylfurfural and levulinic acid: challenges and opportunities. Biomass Bioenerg 72:143-183. https ://doi.org/10.1016/j.biombioe.2014.11.007

Nizamuddin S, Ahmed H, Siddiqui BMTH et al (2018) An overview of microwave hydrothermal carbonization and microwave pyrolysis of biomass. Rev Environ Sci Biotechnol 17:813-837. https://doi. org/10.1007/s11157-018-9476-Z

Patil SK, Lund CR (2011) Formation and growth of humins via aldol addition and condensation during acid-catalyzed conversion of 5-hydroxymethylfurfural. Energy Fuels 25(10):4745-4755

Patil SKR, Heltzel J, Lund CRF (2012) Comparison of structural features of humins formed catalytically from glucose, fructose, and 5-hydroxymethylfurfuraldehyde. Energy Fuels 26:5281-5293. https://doi.org/10.1021/ef3007454

Qi Y, Song B, Qi Y (2016) The roles of formic acid and levulinic acid on the formation and growth of carbonaceous spheres by 
hydrothermal carbonization. RSC Adv 6:102428-102435. https ://doi.org/10.1039/c6ra21312j

Runge T, Zhang C (2012) Two-stage acid-catalyzed conversion of carbohydrates into levulinic acid. Ind Eng Chem Res. https://doi. org/10.1021/ie2021619

Ryu J, Jin D, Ahn DJ (2010) Hydrothermal preparation of carbon microspheres from mono-saccharides and phenolic compounds. Carbon NY 48:1990-1998. https://doi.org/10.1016/j.carbo n.2010.02.006

Sairanen E, Karinen R, Lehtonen J (2014) Comparison of solid acidcatalyzed and autocatalyzed c5 and c6 sugar dehydration reactions with water as a solvent. Catal Lett. https://doi.org/10.1007/s1056 2-014-1350-1

Shen J, Wyman CE (2011) Hydrochloric acid-catalyzed levulinic acid formation from cellulose: data and kinetic model to maximize yields. AIChE J 58:236-246

Singh B, Fang Y, Johnston CT (2016) A Fourier-transform infrared study of biochar aging in soils. Soil Sci Soc Am J 80:613-622. https://doi.org/10.2136/sssaj2015.11.0414

Sluiter A, Hames B, Ruiz R, et al (2012) Determination of structural carbohydrates and lignin in Biomass. Laboratory analytical procedure. NREL/TP-510-42618. US National Renewable Energy Laboratory, Golden, Colorado

Sweygers N, Somers MH, Appels L (2018) Optimization of hydrothermal conversion of bamboo (Phyllostachys aureosulcata) to levulinic acid via response surface methodology. J Environ Manage 219:95-102. https://doi.org/10.1016/j.jenvman.2018.04.105

Swift TD, Bagia C, Choudhary V et al (2014) Kinetics of homogeneous Brønsted acid catalyzed fructose dehydration and 5-hydroxymethyl furfural rehydration: a combined experimental and computational study. ACS Catal 4:259-267. https://doi.org/10.1021/ cs4009495
Tsilomelekis G, Orella MJ, Lin Z et al (2016) Molecular structure, morphology and growth mechanisms and rates of 5-hydroxymethyl furfural (HMF) derived humins. Green Chem 18:1983-1993. https://doi.org/10.1039/c5gc01938a

van Zandvoort I, Wang Y, Rasrendra CB et al (2013) Formation molecular structure, and morphology of humins in biomass conversion: influence of feedstock and processing conditions. ChemSusChem. https://doi.org/10.1002/cssc.201300332

Van Zandvoort I, Koers EJ, Weingarth M et al (2015) Structural characterization of $13 \mathrm{C}$-enriched humins and alkali-treated $13 \mathrm{C}$ humins by 2D solid-state. NMR 17:4383-4392. https://doi.org/10.1039/ c5gc00327j

Wang Q, Guan S, Shen D (2017) Experimental and kinetic study on lignin depolymerization in water/formic acid system. Int J Mol Sci. https://doi.org/10.3390/ijms18102082

Xiong X, Yu IKM, Tsang DCW et al (2019) Value-added chemicals from food supply chain wastes: state-of-the-art review and future prospects. Chem Eng J 375:121983. https://doi.org/10.1016/j. cej.2019.121983

Yoon SY, Han SH, Shin SJ (2014) The effect of hemicelluloses and lignin on acid hydrolysis of cellulose. Energy 77:19-24. https:// doi.org/10.1016/j.energy.2014.01.104

Yu IKM, Tsang DCW (2017) Conversion of biomass to hydroxymethylfurfural: a review of catalytic systems and underlying mechanisms. Bioresour Technol 238:716-732. https://doi.org/10.1016/j. biortech.2017.04.026

Publisher's Note Springer Nature remains neutral with regard to jurisdictional claims in published maps and institutional affiliations. 